\title{
Derechos y justicia procesal imperfecta
}

\author{
Josep Joan MORESO
}

Universitat de Girona

Working Paper n.139

Barcelona 1998 


\section{INTRODUCCIÓN}

La idea de que un sistema político justo debe respetar los derechos básicos de las personas pertenece a los fundamentos de la mayoría de nuestras concepciones filosóficas de la justicia. No es, sin embargo, una idea indiscutida. Algunas concepciones filosóficas niegan este privilegiado lugar a los derechos. Por razones diversas, Jeremy Bentham, Edmund Burke y Karl Marx plantearon diversos desafíos teóricos conducentes a negar el lugar básico de los derechos en la concepción de la justicia ${ }^{1}$. Los derechos eran, para Bentham, nada más que 'nonsense upon stilts'2; una crítica que, desde fundamentos filosóficos distintos, permea los escritos de los autores comunitaristas, críticos de las concepciones liberales de la justicia ${ }^{3}$. Así, Alasdair Maclntyre ha escrito que, en realidad, los derechos no existen y que creer en ellos es como creer en brujas y unicornios.

Obviamente, las críticas de estos autores no se refieren a los derechos legales, conferidos por normas jurídicas, sino a los derechos naturales o humanos, que los iusnaturalistas racionalistas introdujeron en la discusión en la filosofía moderna. Sin embargo, no es a esta polémica a la que va dedicado mi trabajo. Supondré, de la forma que más adelante especificaré con mayor amplitud, que las proposiciones que adscriben derechos humanos a las personas tienen sentido y pueden ser verdaderas y que dichas proposiciones son verdaderas si determinados principios o reglas forman parte de la teoría de la justicia que tomamos como marco de referencia.

La cuestión a la que me referiré es la siguiente: si se acepta una teoría de la justicia entre cuyos principios haya algunos que confieren derechos básicos, ¿estamos, entonces, comprometidos a aceptar algunas consecuencias en el diseño de nuestras instituciones políticas? Y, en concreto, (i) ¿debemos diseñar la estructura política de la sociedad de manera que, al menos, algunos de esos derechos básicos, queden atrincherados en un Bill of Rights que goce de primacía sobre la actividad legislativa ordinaria? y (ii) ¿qué lugar, si alguno, han de tener los órganos jurisdiccionales en la protección de los derechos básicos fijados en el Bill of Rights?

En realidad, la respuesta de los teóricos liberales a estas dos cuestiones suele ser la siguiente: respecto a (i) se afirma que las decisiones mayoritarias $y$, por lo tanto, la soberanía parlamentaria deben estar limitadas por los derechos protegidos constitucionalmente (aunque también pueden quedar fuera de la decisión democrática otros aspectos del diseño constitucional) y respecto a (ii) se 
sostiene que algún tipo de control jurisdiccional de la constitucionalidad ha de establecerse, sea un control difuso en manos de todos los jueces (como en el práctica constitucional norteamericana) sea un control concentrado confiado a un sólo órgano (como en los sistemas de inspiración kelseniana que han adoptado muchas de las democracias de la Europa continental). Ahora bien, dicha respuesta ha sido puesta en cuestión en los últimos años y, por lo que hace a (ii), ha ocupado gran parte de la discusión norteamericana sobre el mecanismo del judicial reviewy la denominada objeción contramayoritaria 4 . De todas formas también (i) ha sido, recientemente, puesto en cuestión -aunque, como veremos, no siempre con argumentos independientes de la crítica a (ii)-; así en el contexto de la propuesta de un Bill of Rights para el Reino Unido ${ }^{5}$ como parte de una reforma constitucional en profundidad, Jeremy Waldron 6 ha elaborado una crítica al diseño institucional de la protección constitucional de los derechos, desde una concepción liberal y democrática de la justicia, que acepta principios que confieren derechos básicos. Algunos aspectos de esta crítica han sido aceptados también por Juan Carlos Bayón7 y por Roberto Gargarella 8 .

Frente a estas críticas, defenderé que, si se acepta una teoría de la justicia que contiene principios que establezcan derechos básicos, entonces hay poderosas razones para que al menos algunos de estos derechos se conviertan en el diseño institucional justo en derechos constitucionales con cierta primacía sobre las decisiones legislativas ordinarias $y$, también, que hay poderosas razones para confiar en los órganos jurisdiccionales algunos aspectos de la protección de estos derechos constitucionales.

Mi argumento transcurrirá de la siguiente manera. En (II), trataré de mostrar que las ideas que defiendo son neutrales respecto a la metaética que se adopte, son también neutrales respecto a la ética normativa que soporte la teoría de la justicia con el requisito de que dicha teoría de la justicia comprenda principios que establezcan derechos, y que mi argumento no depende de un concepto concreto de derechos morales o humanos. En (III), presentaré los argumentos de los críticos a la idea de la primacía de los derechos constitucionales, siguiendo básicamente las ideas de Waldron. En (IV), y siguiendo a Rawls, presentaré una vía de transición entre la teoría de la justicia y el diseño de las instituciones políticas básicas. En (V), intentaré mostrar cómo dicho mecanismo de transición justifica la tesis de la primacía de los derechos constitucionales y qué papel mínimo han de jugar los órganos jurisdiccionales para proteger dicha primacía. En (VI), por último, propondré varias líneas de réplica a los críticos de las ideas que sostengo. 


\section{CUESTIONES CONCEPTUALES}

\section{(a) La tesis de los derechos es metaéticamente neutral}

Es cierto que, a menudo, los defensores de los derechos humanos han concebido que dichos derechos tenían algún tipo de existencia objetiva. $O$ bien porque eran concebidos como facultades morales que residen en la naturaleza humana o bien porque eran concebidos como otorgados por principios o normas morales, cuya validez objetiva le venía dada a la razón humana. Pero para las tesis que pienso vindicar no es necesario asumir un compromiso ontológico tan fuerte. Puede argüirse que los principios que establecen derechos son sólo propuestos o adoptados por determinadas teorías de la moral que tratan de reconstruir nuestras intuiciones y prácticas morales. Así, J.L. Mackie, un conocido no-cognoscitivista en materia moral ${ }^{9}$, ha escrito 10 :

It is true that rights are not plausible candidates for objective existence. But neither are goods or intrinsic goals, conceived as things whose nature itself requires that they should be pursued, or duties taken as intrinsic requirements, as constituting something like commands for which there need be, and is, no commander, which issue from no source. A belief in objective prescriptivity has flourished within the tradition of moral thinking, but it cannot in the end be defended. So we are not looking for objective truth or reality in a moral system. Moral entities -values or standars or whatever they may be- belong within human thinking and practice: they are either explicitly or implicitly posited, adopted, or laid down. And the positing of rights is no more obscure or questionable than the positing of goals or obligations.

Según esta concepción, la verdad de una proposición moral como: 'Los niños tienen derecho a no ser torturados' depende de que una norma o principio de una teoría moral establezca que los niños tienen derecho a no ser torturados, como un principio básico o como un principio derivado de la teoría. Los fundamentos de la teoría quedan en esta presentación en la opacidad. Para algunos, las teorías morales podrán ser contrastadas con una determinada realidad moral; para otros, las teorías morales son construidas o proyectadas sobre el mundo. Mis argumentos no necesitan tomar partido en esta polémica metaética (aunque deseo añadir que mi posición es, en este punto, nocognoscitivista). 
Alguien podría argüir que las concepciones no-cognoscitivistas no consiguen capturar un rasgo central de las teorías de los derechos humanos, e.g., la universalidad de los derechos. Esta crítica tiene fuerza si la universalidad supone algún tipo de validez objetiva; ahora bien, que los derechos humanos son universales será entendido aquí en el sentido de que estos derechos se adscriben en la teoría a todos los seres humanos por el mero hecho de serlo 11 . En este sentido y conforme a la teoría son universales.

\section{(b) La tesis de los derechos es (parcialmente) neutral desde el punto de vista de la ética normativa}

Mi argumento tampoco necesita la adscripción a una teoría normativa concreta que establezca derechos. De hecho, es compatible con todas las éticas normativas que contengan reglas que establezcan derechos. Sólo quedan excluidas aquellas concepciones de la justicia que no dejen ningún lugar para los derechos. Así, tal vez, algunas formas particularmente extremas de utilitarismo del acto, para las cuales la corrección moral de las acciones depende únicamente de las consecuencias de esa acción individual para algún fin colectivo -e.g., la felicidad colectiva, o la maximización de las preferencias-; o algunas formas de comunitarismo, para las cuales el lenguaje de la moral es el lenguaje de las virtudes que permiten a las personas realizarse en una comunidad determinada y el lenguaje de los derechos es únicamente una perversión ilustrada del lenguaje moral.

Ahora bien, mi argumento no excluye aquellas teorías de la justicia no fundadas en derechos, sino en deberes o en objetivos; siempre que estas teorías contengan reglas que confieran derechos, aunque estas reglas sean derivadas de otros principios más básicos que establecen deberes u objetivos a alcanzar. Como es sabido, Ronald Dworkin ${ }^{12}$ propuso clasificar las teorías políticas en teorías basadas en objetivos, teorías basadas en deberes y teorías basadas en derechos. Las teorías basadas en objetivos tienen como principio fundante la realización de algún objetivo colectivo, como el bienestar general. Las teorías basadas en deberes tienen como principios fundantes algunas normas que establecen aquello que estamos requeridos a hacer. Las teorías basadas en derechos tienen como principios fundantes algunas normas que confieren derechos básicos. El utilitarismo es, por ejemplo, un caso de teoría fundada en objetivos. La moral kantiana es un ejemplar de teoría fundada en deberes. La teoría de la justicia de Rawls es un buen ejemplo de teoría fundada en derechos. Voy a tratar de mostrar, sin embargo, las razones por las cuales mi argumento no necesita comprometerse con ninguna de estas concepciones 13 . 
Aunque las teorías utilitaristas no tienen entre sus fundamentos principios que establezcan derechos, es posible que tales principios sean derivables en su teoría. Así, L.W. Sumner considera que el fundamento más adecuado para los derechos se halla en una particular versión del utilitarismo y escribe ${ }^{14}$ :

A consequentialist theory of rights tells us that a right is genuine just in case the social policy of recognizing it in the appropiate rule system is the best means of promoting some favoured goal.

Lo mismo ocurre con las teorías fundadas en deberes. Es posible que alguien piense que el derecho a no ser torturado no es fundamental en la teoría, ni siquiera está fundado en otro derecho fundante como el derecho a la integridad física o psíquica, porque el fundamento último de ese derecho no se halla en el interés básico a no ser torturado de las personas que podrían sufrir la tortura, sino que se halla más bien en que la tortura degrada al torturador, elimina su humanidad y socava su integridad como ser racional 15 . La moral kantiana es un caso especialmente claro de teoría fundada en deberes, el cumplimiento del deber es previo y fundante de forma que derrota siempre consideraciones de objetivos y, tal vez, de derechos. Así sucede en Kant, por ejemplo, con el deber de decir la verdad ${ }^{16}$.

Por lo tanto, la cuestión de qué consecuencias tiene para el diseño institucional de las instituciones políticas la aceptación de derechos en nuestra teoría de la justicia, no depende de que dicha teoría sea una teoría basada en derechos. Que los principios que establezcan derechos sean fundantes en la teoría -se comporten como axiomas- o sean derivados de otros principios más básicos de la teoría -se comporten como teoremas- es una cuestión que no es necesario dilucidar aquí. Lo único relevante es que la teoría de la justicia en cuestión sea capaz de acomodar en su seno principios, fundantes o derivados, que establezcan derechos.

\section{(c) Algunas observaciones sobre el concepto de derechos morales}

El argumento que presento de las proposiciones jurídicas que adscriben derechos sólo se compromete con un análisis como el siguiente. Sea la proposición expresada por el enunciado

(1) $X$ tiene derecho moral a hacer $A$,

(1) ha de ser interpretada como

(1') La concepción moral más plausible, $\mathrm{CM}$, atribuye a $\mathrm{X}$ el derecho a hacer $A$. 
CM puede ser una teoría construida o proyectada por los seres humanos, no necesita ser una teoría cuyos principios sean verdaderos objetivamente ni nada parecido. Así las discusiones sobre si A tiene o no un determinado derecho moral son, en realidad, discusiones acerca de la plausibilidad de determinadas teorías morales. De esta forma, si alguien piensa que hay alguna CM que es objetivamente verdadera, entonces para él esta CM es la más plausible. Pero ello no excluye a los no objetivistas en materia ética de la discusión, un no objetivista puede seguir en desacuerdo acerca de que esa sea la concepción moral más plausible. Entonces, el objetivista deberá dar argumentos morales para convencer al no-objetivista, que podrá replicar con otros argumentos morales. Esto muestra que la moral es una cuestión, fundamentalmente de argumentación y, por esta razón, es explicable que la creencia en la objetividad moral no tenga demasiada relevancia en las cuestiones de ética normativa. El debate acerca de si la esclavitud es injusta, por ejemplo, más que un debate sobre si hay algún hecho en el mundo que haga injusta a la esclavitud, es un debate acerca de la razonabilidad de prohibir la esclavitud.

Para esta concepción, la noción de derechos morales no es más controvertible que la noción de derechos legales. Que alguien tiene un derecho legal significa que hay algún sistema jurídico que se lo concede, de forma análoga que alguien tiene un derecho moral significa que hay algún sistema moral que se lo concede.

Por estas razones, un aspecto de la conocida crítica de Bentham a la noción de derechos naturales queda sin efecto. Para Bentham, los derechos legales son como los hijos de las normas jurídicas, dado que no existen las normas del Derecho Natural, entonces los derechos naturales son como un hijo que nunca tuvo un padre. A veces los derechos morales son concebidos metafóricamente como una muralla contra la tiranía, pero Bentham añade la sombra de una muralla no es una muralla, y los derechos morales son como una sombra sin muralla17. Ahora bien, dado que la idea de norma moral, tal como aquí ha sido presentada, no parece cuestionable tampoco la noción de derechos morales lo es ${ }^{18}$. Cuestión distinta, a la que no me referiré aquí, es que Bentham pensara que la noción de derechos morales fuera normativamente perniciosa, porque estuviera reñida con su interpretación del principio de utilidad 19 .

Abandonada la idea de que los derechos sólo pueden ser establecidos por el derecho positivo, nos queda por determinar qué tipo de reglas y cómo dichas reglas (jurídicas, morales, o de otro tipo) conceden derechos. Un conocido 
análisis de los derechos legales puede servirnos de ayuda, me refiero al análisis de Wesley N. Hohfeld20. Como es sabido, el análisis de Hohfeld pone de manifiesto que los enunciados como ' $X$ tiene derecho a $A$ ' son ambiguos $y$ pueden referirse a alguna de las siguientes situaciones (o a alguna combinación de ellas):

(i) Puede ser que ' $X$ tiene derecho a $A$ ' signifique ' $X$ no tiene el deber hacia otra persona $Y$ o hacia un conjunto de personas de no hacer A'. Teniendo en cuenta que las proposiciones que adscriben derechos siempre suponen la existencia de algún sistema de reglas, el enunciado ' $X$ tiene derecho a $A$ ' puede ser analizado como

(a) No existe ninguna regla en el sistema $S$ que prohiba a $X$ hacer $A$.

Hohfeld denominó a este sentido de tener un derecho 'privilege', o como también se denomina, 'liberty-right'21.

(ii) Pero también es posible que ' $X$ tiene derecho a $A$ ' sea entendido como ' $Y$ (una persona $O$ un conjunto de personas) tienen el deber de facilitar que $X$ consiga A'. A veces, el deber de $Y$ consistirá en omitir ciertas acciones, a veces consistirá en realizar ciertas acciones. Así, decir ' $X$ tiene el derecho de alimentos respecto a sus padres' significa 'Los padres de $X$ tienen el deber de alimentos hacia X'. El análisis comporta

(b) Existe una regla en el sistema $S$ que obliga a $Y$ a hacer que $X$ obtenga $A$ (o a no impedir que $X$ haga $A$ ).

Esta posición es denominada por Hohfeld, un 'claim-right'. Los claim-rights siempre están correlacionados con deberes de actuar u omitir.

(iii) Otras veces ' $X$ tiene derecho a $A$ ' se usa en el sentido del poder, capacidad o competencia que $X$ tiene de producir cambios normativos. Así ' $X$ tiene derecho a otorgar testamento' significa ' $X$ tiene el poder de otorgar testamento', lo que puede sumarizarse como

(c) Existe una regla que otorga a $\mathrm{X}$ competencia para testar.

Este caso es denominado por Hohfeld, 'power-right'22. Si alguien tiene el poder normativo de hacer $\mathrm{A}$, habrá otros que están sujetos a dicho poder.

(iv) Por último, al decir ' $X$ tiene derecho a $A$ ' podemos significar también que $X$ es inmune respecto a $Y$ (puede ser una persona 0 un conjunto de personas), esto es, que $Y$ no puede alterar la situación normativa de $X$ en 
relación a A. Así son, a menudo, entendidos los derechos constitucionales. Mi derecho a expresarme libremente, no sólo es un liberty-right (no hay reglas que me prohiban hacerlo) y un claim-right (hay reglas que obligan a otros a no impedírmelo) sino que hay reglas que declaran inválidas las normas que me prohiban hacerlo (así las disposiciones legislativas). El análisis requiere algo como

(d) En el sistema $S$ son inválidas las reglas que prohiban a $X$ hacer $A$.

Esta posición es denominada por Hohfeld 'immunity-right', cuyo correlato es una carencia de poder (una disability) por parte de otros.

Los derechos, desde el punto de vista jurídico, pueden ser contemplados como una de estas cuatro posiciones hohfeldianas o como una combinación de algunas de ellas.

Los derechos morales, en cambio, parecen tener una relación más estrecha con la categoría de claim-rights. Cuando se toma esta línea de análisis, es preciso determinar todavía cuál es la relación entre el claim de $\mathrm{X}$ y los deberes correlativos de Y. Al respecto, dos concepciones son las predominantes, la denominada 'Choice Theory'23 -que identifica al portador $X$ del derecho en virtud del control que tiene sobre el deber correlativo de $\mathrm{Y}$ - $\mathrm{y}$ la 'Benefit o Interest Theory'24 -en este caso el deber correlativo de $Y$ al derecho de $X$ está fundado en algún interés de $X$, algún aspecto del bienestar de $X$ es una razón para mantener el deber de $\mathrm{Y}$-.

Afortunadamente, no es preciso para mi argumento entrar en esta polémica. Los derechos morales pueden ser alguna posición hohfeldiana como la de claim-rights -según la teoría de las decisiones protegidas o según la teoría de los intereses protegidos- o pueden ser los títulos que justifican el poseer alguna de estas posiciones ${ }^{25}$, o bien -algo semejante a lo anterior- la justificación moral del hecho de tener un derecho convencional entendido como una de las posiciones hohfeldianas 26 . Para mi argumento es suficiente rescatar dos aspectos que son comunes a todos estos análisis del concepto de derechos morales: (i) por una parte, las proposiciones que adscriben derechos morales presuponen la existencia (descubierta o construida) de algún sistema de reglas morales y (ii) el hecho de adscribir determinados derechos morales a las personas es una razón que justifica adscribirles determinados derechos institucionales. 


\section{DERECHOS MORALES VERSUS DERECHOS CONSTITUCIONALES}

Jeremy Waldron presenta la tesis contraria a la supremacía de los derechos constitucionales y a la introducción de un control jurisdiccional de constitucionalidad con las siguientes palabras 27 :

... there is no necessary inference from a right-based position in political philosophy to a commitment to a Bill of Rights as a political institution along with an American-style practice of judicial review.

Waldron no sólo intenta defender esta tesis negativa, sino también la tesis positiva de que hay razones morales para no asumir compromiso alguno con el atrincheramiento de los derechos y para rechazar el control jursidiccional de constitucionalidad.

Sus argumentos pueden ser presentados de la siguiente manera:

(i) En primer lugar, tener un derecho moral a algo no implica que se deba tener un derecho legal a ello. Waldron sugiere la posiblidad de que, e.g., un amigo mío tenga un derecho moral a que le revele una información importante para él y me diga 'tengo derecho a saberlo' sin apelar a ninguna norma jurídica 28 . Concedo este punto sin mayor argumentación. Pero de ello sólo se deduce que tener un derecho moral no siempre implica tener un derecho legal. Sólo algunos derechos morales están relacionados con nuestros derechos legales, aquellos que guardan relación con el diseño justo de nuestras instituciones políticas.

Sin embargo, también para este último caso la inferencia le parece cuestionable a Waldron. Así, según Waldron29,

(1) $X$ tiene un derecho moral a $A$, no implica necesariamente

(2) $\mathrm{X}$ (moralmente) debe tener un derecho legal a $\mathrm{A}$, sino que, si implica algo acerca del derecho, presumiblemente implica

(3) El derecho debe ser de tal manera que $X$ logre $A^{30}$.

Ahora bien, si se tiene en cuenta el análisis hohfeldiano, es obvio -como el mismo Waldron reconoce- que (3) supone la existencia de alguna regla que atribuye a $\mathrm{X}$ alguna de las posiciones hohfeldianas. Estas posiciones hohfeldianas van, habitualmente, unidas a la titularidad de una acción procesal de $\mathrm{X}$ respecto a $\mathrm{A}$. Es cierto, que en algunos casos de escasez de recursos en 
políticas de bienestar, el derecho -en lugar de otorgar acciones procesales individuales- concede una discreción limitada a los poderes administrativos para gestionar lo más eficientemente posible esos recursos. Pero ello no representa que $X$ no tenga derecho a $A$, sino que el derecho de $X$ puede entrar en conflicto con el derecho de $Y$ sobre el mismo recurso, y si se justifica que $Y$ lo necesita más que $\mathrm{X}$, entonces los poderes administrativos pueden asignarlo a $\mathrm{X}$.

(ii) Sin embargo, el mismo Waldron no concede mucho peso a la primera objeción y se pregunta si es plausible sostener que alguien que adhiera a (2) deba adherir también a

(4) $\mathrm{X}$ (moralmente) debe tener un derecho constitucional a A.

Esto es, el diseño de las instituciones políticas debe ser de tal manera que $X$ tenga un immunity-right respecto a $A$, lo que representa que la legislatura carece de competencia para abolir el derecho de $\mathrm{X}$ sobre $\mathrm{A}$. Los derechos constitucionales configuran lo que ha sido denominado un 'coto vedado' excluido de la negociación y el compromiso parlamentario 31 . Es la tesis del coto vedado lo que Waldron cuestiona, y ello por dos razones: (a) porque si ese coto vedado no está reconocido a nivel constitucional, entonces el defensor de esta tesis debe luchar por una reforma constitucional muy costosa o, si ya existe un Bill of Rights pero un derecho concreto no es reconocido, entonces debe luchar o bien por la reforma o bien porque sea reconocido por vía interpretativa y (b) todavía más importante, porque la rigidez verbal que surge de encerrar los derechos en determinadas fórmulas canónicas, como sucede en las cláusulas constitucionales que expresan el coto vedado, llevan las discusiones sobre su significado lejos de la discusión moral abierta, las conducen a discusiones escolásticas sobre el significado de determinados textos, así ¿es un tipo de expresión, protegido por la libertad de expresión, la pornografía, o los insultos raciales, o quemar la bandera nacional? 32 .

Es obvio que lo mismo sucede cuando los derechos son reconocidos a nivel legislativo, pero en este último caso las discusiones jurisprudenciales pueden ser eliminadas con una mera revisión de la legislación.

Querer atrincherar constitucionalmente los derechos, añade Waldron33, es una muestra de desconfianza hacia el resto de conciudadanos. Una desconfianza que se compadece mal con el respeto por su autonomía que fundamenta, precisamente, el atribuirles los derechos. 
(iii) Este último elemento guarda relación con otro hecho ampliamente conocido acerca de los derechos. El hecho de que cuáles sean los derechos que han de estar en el coto vedado es una cuestión ampliamente controvertida en sociedades plurales. El hecho del pluralismo y del desacuerdo no puede ser ignorado en nuestra teoría de la justicia. La teoría de los derechos ha de ser acompañada por alguna teoría de la autoridad. Una teoría susceptible de determinar quién debe decidir las cuestiones en caso de desacuerdo. De nada sirve afirmar que si las personas están en desacuerdo acerca de alguna cuestión, entonces la cuestión ha de dirimirse usando la regla de la mayoría como instrumento de decisión, siempre que no sean violados derechos individuales 34 . Puesto que si el desacuerdo es también sobre los derechos, entonces necesitamos algún procedimiento decisorio acerca de este desacuerdo. La regla decisoria no puede ser 'Elige la respuesta justa', precisamente porque no estamos de acuerdo sobre cuál sea la respuesta justa. Entonces, debemos elegir entre un procedimiento en el cual la voz de todos sea escuchada y otro como el control jurisdiccional de constitucionalidad- en donde prevalezca la voz de los miembros de un Tribunal. Esto nos lleva al próximo punto de crítica.

(iv) Confiar el coto vedado a un Tribunal (en Estados Unidos a todos los tribunales y, en último caso, a la Corte Suprema; en España o en Italia, al Tribunal Constitucional) no es aceptar como regla de decisión en caso de desacuerdo acerca de si $X$ tiene derecho básico a $A$, la regla siguiente: ' $X$ tiene derecho a $A$ si se deriva de la mejor teoría de la justicia', sino ' $X$ tiene derecho a A -en el caso español- si se lo concede la mayoría de los magistrados del Tribunal Constitucional'35. Si tomamos esta regla de decisión, ignoramos el derecho de todos a participar en las decisiones que les afectan. La participación de todos en las decisiones públicas es valiosa porque reconoce la dignidad, autonomía y capacidad de autogobernarse de las personas. Precisamente las características que hacen plausible adscribir derechos morales a las personas. Es obvio que la democracia representativa, al confiar las decisiones a la regla de la mayoría de la legislatura, no es un sistema democrático perfecto; pero las voces de todos son más escuchadas que en el caso de confiar la decisión a unos pocos.

Roberto Gargarella subraya esta línea de argumentación al insistir en el origen conservador y elitista de la insititución de la judicial reviewen Estados Unidos y demandar un mayor peso para la deliberación de los ciudadanos en todas las cuestiones que les afectan36. 
En conclusión, siempre hay algo erróneo en denegar los derechos morales de uno; pero no hay nada específicamente erróneo acerca de la denegación de los derechos morales a manos de la mayoría de sus conciudadanos. Una reflexión que Waldron completa de la siguiente manera 37 :

In the end, I think, the matter comes down to this. If a process is democratic and comes up with the correct result, it does no injustice to anyone. But if the process is non-democratic, it inherently and necesarily does an injustice, in its operation, to the participatory aspirations of the ordinary citizen. And it does this injustice, tyrannizes in this way, whether it comes up with the correct result or not.

\section{IV) LA DEMOCRACIA CONSTITUCIONAL: UN CASO DE JUSTICIA PROCESAL IMPERFECTA}

John Rawls 38 ha distinguido tres tipos de justicia procesal: la justicia procesal pura, la justicia procesal perfecta y la justicia procesal imperfecta. En el caso de la justicia procesal pura, consideramos justo un resultado por haber seguido un determinado procedimiento, no disponemos en este caso de criterio alguno independiente para juzgar la justicia del resultado. El resultado de un juego de azar, e.g. un juego de naipes, es justo si se han seguido las reglas que señalan el procedimiento del juego, no disponemos de ningún criterio independiente de las propias reglas procesales para evaluar la justicia del resultado. Los principios de justicia elegidos en la posición original son también un caso de justicia procesal pura, esos son los principios adecuados porque son los que elegiríamos si siguiéramos las reglas que configuran la posición original. En palabras de Rawls 39 :

Thus, rational autonomy is modeled by making the original position a case of pure procedural justice. That is, whatever principles the parties select from the list of alternatives presented to them are accepted as just. Put another way, following the idea that citizens themselves (via their representatives) are to specify the fair terms of their cooperation (and putting aside for the present the criterion of reflective equilibrium), the outcome of the original position yields, we conjecture, the appropiate principles of justice for free and equal citizens.

En la justicia procesal perfecta, en cambio, disponemos de un criterio ya previo e independiente de lo que es justo, y el procedimiento es diseñado para asegurar que el resultado satisfaga el criterio. Rawls pone el ejemplo de la división de una tarta, si aceptamos que el resultado justo es que cada uno tenga 
una porción igual, entonces el procedimiento que asegura dicho resultado es simple (suponiendo que los destinatarios de la tarta son seres racionales): se estipula que aquel que corta la tarta se queda con la última porción.

En los casos de la justicia procesal imperfecta, por último, también disponemos de un criterio independiente para evaluar la justicia del resultado, ahora bien no nos es posible designar un procedimiento que nos asegure el logro de resultados justos en todos los casos. Rawls ilustra este supuesto mediante los procesos penales. El resultado deseado es que el acusado sea declarado culpable si y sólo si ha cometido el delito por el que es juzgado. Sin embargo, parece imposible diseñar las normas jurídicas de manera que siempre se logre el resultado correcto. Desgraciadamente, los casos de justicia procesal perfecta son raros en cuestiones de gran interés práctico $y$, a menudo, debemos conformarnos con la justicia procesal imperfecta.

Ahora bien, ¿son los procedimientos que diseñamos para tomar decisiones en el ámbito de nuestras instituciones políticas un caso de justicia procesal pura, o un caso de justicia procesal imperfecta -supongamos que estamos de acuerdo en la imposibilidad en este caso de supuestos de justicia procesal perfecta-?

La democracia, y entenderé ahora por 'democracia' un procedimiento de decisión mediante la regla de la mayoría, es un sistema con muchas ventajas sobre cualquiera de las alternativas disponibles. Sea la democracia representativa o directa, reconoce en alto grado la voz de todos a la hora de tomar decisiones públicas. No obstante, la regla de la mayoría no puede ser entendida como un caso de justicia procesal pura para aquellas concepciones de la justicia que reconocen principios que atribuyen derechos. Es siempre posible que una decisión tomada por la mayoría viole algunos de los derechos de las personas que la teoría de la justicia reconoce. De hecho, los procedimientos políticos son siempre, para teorías de la justicia que reconocen derechos, supuestos de justicia procesal imperfecta. $Y$ ello porque, por una parte tenemos un criterio independiente para evaluar la corrección de los resultados: los principios de justicia establecidos en la teoría $y$, por otra parte, ningún procedimiento político garantiza el logro de un resultado justo. Rawls lo señala con estas palabras 40 :

In fact, there is no scheme of procedural political rules which guarantees that unjust legislation will be not enacted. In the case of a constitutional regime, or indeed of any political form, the ideal of perfect procedural 
justice cannot be realized. The best attainable scheme is one of the imperfect procedural justice.

Por lo tanto, el problema que debemos resolver es cómo diseñar procedimientos políticos que aseguren en la mayor medida posible resultados de acuerdo a los principios de justicia 41 .

Supongamos que excluimos determinadas formas de democracia directa en estado puro por las razones conocidas, nos quedan entonces, al menos, dos posibilidades: (a) o bien pensamos que algún tipo de democracia representativa con (al menos) una cámara elegida por los ciudadanos y tomando todas las decisiones sobre cualquier cuestión mediante la regla de la mayoría, es la que alcanzará con mayor probabilidad resultados justos -el denominado, a veces, 'modelo de Westminster' 42 - o bien establecemos algunas restricciones a las decisiones que han de ser alcanzadas mediante la regla de la mayoría, dejando fuera del alcance de dicha regla algunas cuestiones -un esquema denominado 'democracia dualista'43.

Una de las formas más atractivas de defender el modelo monista de democracia es a través de la tesis del valor epistémico de la democracia. Según Carlos S. Nino 44 :

...la democracia, a través de la discusión y de la decisión mayoritaria que es inherente al proceso democrático, tiene un valor epistemológico, es decir, es una vía apta para llegar a soluciones que tienen una mayor probabilidad de ser moralmente correctas que las soluciones que se dictan a través de otros procedimientos. Esto es así, porque la discusión generalizada, amplia, abierta y la decisión mayoritaria promueven procedimientos que tienden a la imparcialidad y al conocimiento de los hechos relevantes, porque hace que todos o que una buena parte de la población hagan conocer a través del proceso democrático cuáles son sus intereses y que haya una tendencia a tomar esos intereses en cuenta para lograr formar coaliciones mayoritarias y que esas coaliciones no se rompan bajo la presión de otros grupos.

Sin embargo, el mismo Nino añade que de esta misma justificación de la democracia surge una limitación a los órganos mayoritarios: la mayoría no tiene legitimidad para decidir sobre la restricción de las condiciones y los presupuestos que hacen del procedimiento democrático un mecanismo apto para encontrar soluciones correctas 45 . Ahora bien, este es también un argumento rechazado 
por Waldron porque, dice, la verdad acerca de la participación y del proceso es tan compleja y discutida como cualquier otra cuestión en política y añade 46 :

People disagree about how participatory rights should be understood and about how they should be balanced against other values. They have views on constitutional boundaries, proportional representation, the frequency of elections, the funding of parties, the relation between free speech and political advertising, the desirability of referendums, and so on. Respect for their political capacities demands that their voices be heard and their opinions count on these matters, as much as on any matter. Honouring self-government does not stop at the treshold from substance to procedure.

Creo que en este punto Waldron lleva razón. Si no se justifica situar en el coto vedado de los derechos constitucionales los, digamos, derechos substantivos porque al ser controvertidos atrincherarlos ignoraría la importancia central de la deliberación democrática, el mismo argumento vale para los derechos procesales de participación política. Vale la pena, por tanto, analizar la segunda de nuestras alternativas: el modelo de democracia dualista entendido como coto vedado plus regla de la mayoría.

Analizaré ahora cómo podría definirse la secuencia que conduzca a un modelo como el de democracia dualista o, como también es denominado, de democracia constitucional.

Rawls 47 imagina una secuencia en cuatro etapas en el establecimiento de las cuestiones de justicia por parte de seres racionales. La primera etapa consiste en la posición original en la que se eligen los dos principios de justicia. La segunda etapa estipula las normas constitucionales que aseguran el principio de igual libertad para todos. La tercera etapa tiene como objetivo el establecimiento de las reglas legislativas de acuerdo con los principios de justicia -respetados los derechos atrincherados en la segunda etapa, las decisiones deben adecuarse al principio de la diferencia-. La cuarta etapa es la de la aplicación de las reglas generales a los casos individuales por parte de los órganos de aplicación. Cada una de estas etapas presupone un progresivo levantamiento del velo de la ignorancia que, por una parte, permite articular las normas adecuadas para cada sociedad en concreto y, por otra, permite hacerlo de forma justa, puesto que en todas las etapas deben respetarse los principios de justicia. 
Nos interesa ahora el tránsito de la primera a la æegunda etapa. Según Rawls, es urgente para los ciudadanos lograr un acuerdo acerca de lo que constituye los elementos esenciales de carácter constitucional. Son de dos tipos 48 :

a. Fundamental principles that specify the general structure of government and the political process: the powers of the legislature, executive and the judiciary; the scope of majority rule; and

b. Equal basic rights and liberties of citizenship that legislative majorities are to respect: such as the right to vote and to participate in politics, liberty of conscience, freedom of thought and of association, as well as the protections of the rule of law.

Rawls aclara que el principio que protege los derechos básicos y las libertades, el coto vedado, debe ser distinguido del principio referido a las desigualdades sociales y económicas. Ambos son principios de justicia, pero mientras el primero cubre la libertad de movimiento, la elección libre de trabajo y el derecho a un mínimo social que satisfaga las necesidades básicas de los ciudadanos, no llega a cubrir el principio de igualdad de oportunidades y el principio de la diferencia. Las razones de Rawls para establecer esta distinción son: a) los dos tipos de principios especifican diferentes funciones en la estructura básica, b) es más urgente determinar los elementos esenciales que afectan a las libertades básicas, c) es más fácil averiguar si estos elementos esenciales han sido satisfechos y d) es mucho más fácil alcanzar un acuerdo acerca de los derechos básicos y las libertades si se presenta en sus líneas generales y no en detalle 49 .

La conclusión es obvia 50 :

...constituional democracy is dualist: it distinguishes constituent power from ordinary power as well as the higher law of the people from the ordinary law of legislative bodies. Parlamentary supremacy is rejected.

En este modelo, la soberanía no reside en la legislatura -la legislatura no es omnicompetente-, sino que reside en el poder constituyente. La Constitución, elaborada por el poder constituyente, es la expresión de la voluntad de este poder soberano. El poder legislativo (como el ejecutivo y el judicial) son tales porque han sido instituidos por el constituyente y tiene el límite, entre otros, del coto vedado que protege los derechos constitucionales. Habitualmente este poder constituyente confía en un poder constituyente derivado la reforma de la Constitución (aunque también es posible, como hace la Ley Fundamental en Alemania, atrincherar algunos derechos de una vez para siempre). En este 
sentido, la democracia no es una forma de gobierno sino más bien una forma de soberanía 51 .

En este modelo, la regla de la mayoría es el sistema de decisión en manos de los cuerpos legislativos con las restricciones establecidas por los elementos esenciales de carácter constitucional. En este ámbito y con las restricciones señaladas, la tesis del valor epistémico de la democracia recobra fuerza. Como Rawls sugiere, si las leyes votadas están en el ámbito de aquellas que razonablemente establecen legisladores racionales que intentan seguir los principios de justicia, entonces la decisión de la mayoría está prácticamente dotada de autoridad, aunque no definitivamente. La situación es una de justicia procesal cuasi-pura52.

Rawls, sin embargo, no trata de argüir en favor de que a democracia constitucional sea superior al modelo de democracia monista para una concepción política razonable de la justicia. Sugiere que esta cuestión depende de las condiciones históricas, de la cultura política y de las instituciones políticas concretas de un país particular 53 .

En el próximo epígrafe trataré de argüir que existen razones para preferir el modelo de democracia constitucional al modelo de democracia monista.

\section{LAS CIRCUNSTANCIAS DE LA PRIMACÍA DE LA CONSTITUCIÓN54}

Es posible, según creo, ofrecer una explicación de la primacía de la Constitución sobre el resto de la legislación que justifique trazar un coto vedado para proteger los derechos constitucionales de la actividad legislativa ordinaria.

En realidad, la democracia representativa, entendida ahora como un método de decisión mediante el voto de la mayoría, está en contradicción con la idea de primacía de la constitución, entendida como restricción al conjunto de decisiones que pueden tomarse por mayoría. Es lo que ha sido conocido como paradoja de la democracia, según la cual: 'each generation wants to be free to bind its successors, while not being bound by its predecessors' 55 .

Jon Elster ha elaborado una analogía entre determinados mecanismos de lo que denomina racionalidad imperfecta -de carácter individual- y el caso de la paradoja de la democracia. El ejemplo usado por Elster es el de Ulises y las sirenas. Como es sabido, Ulises, sabiéndose débil para comportarse 
racionalmente al oír los cantos de las sirenas y queriendo realizar su deseo de oír dichos cantos, diseñó una estrategia consistente en hacer que sus marineros lo ataran al mástil de la nave y se taponaran los oídos con cera. Ulises no era completamente racional, pues un ser racional no habría necesitado este recurso. Tampoco era el pasivo e irracional vehículo de sus cambiantes caprichos y deseos, pues era capaz de alcanzar por medios indirectos el mismo fin que una persona racional habría podido alcanzar de manera directa. Ser débil y conocer su debilidad es lo que le llevaba a diseñar recursos de racionalidad imperfecta cn el objetivo de superar su debilidad de voluntad 56 .

Este mecanismo de Ulises es un mecanismo de precompromiso, de atarse a sí mismo y: 'atarse a sí mismo es llevar a cabo cierta decisión en el tiempo $t_{1}$ para aumentar la probabilidad de llevar a cabo otra decisión en el tiempo $t_{2}{ }^{\prime}$.

Mecanismos de precompromiso son usados por los seres humanos en múltiples situaciones de debilidad de la voluntad: así en estrategias para dejar de fumar (e.g. pasar una temporada en un lugar donde no haya cigarrillos al alcance de uno), para adelgazar (e.g. no tener en casa, o en el lugar donde se pase la mayor parte del tiempo, los alimentos que uno más desea), etc. Atarse a sí mismo en estas situaciones consiste en excluir determinadas decisiones del futuro, para preservar una decisión del pasado que se valora positivamente.

La analogía con los mecanismos de decisión colectiva consiste en sugerir que también para las decisiones colectivas vale el precompromiso: excluir la posibilidad de tomar determinadas decisiones en el futuro para preservar contenidos especialmente valiosos. Así puede comprenderse la distinción, habitual en teoría política, entre el poder constituyente y el poder constituido. De nuevo en palabras de Elster57:

Only the constituent assembly is a political actor, in the strong sense of la politique politisante; all later generations are restricted to la politique politisée, or to the day-to-day enactment [i.e., acting-out or implementation] of the ground rules.

La idea del precompromiso se halla adecuadamente expresada en el ideal de la democracia constitucional. Determinadas materias (los derechos fundamentales, la estructura territorial del Estado, la división de poderes, etc.) quedan fuera de la agenda política cotidiana y, por lo tanto, del debate público y del debate legislativo -de la regla de la mayoría, que sólo vale para la agenda política del resto de cuestiones-. 
El mecanismo del precompromiso puede contemplarse como una explicación contextual de la primacía de la Constitución, pertenece a las circunstancias en que es posible referirse a la primacía de la constitución, de forma semejante a como, por ejemplo, David Hume pensaba que la escasez moderada pertenece a lo que pueden denominarse circunstancias de la justicia58. Estas circunstancias no forman parte de una explicación conceptual de la noción de justicia, pero constituyen el contexto donde dicha explicación debe ser producida.

Si las decisiones colectivas son susceptibles de ser afectadas por la debilidad de las voluntades concurrentes, entonces es razonable pensar en introducir mecanismos procesales para la toma de decisiones que introduzcan la racionalidad indirectamente. Por otra parte, si nuestra teoría de la justicia establece derechos individuales, entonces es preciso diseñar mecanismos susceptibles de afianzar el respeto de dichos derechos. Por lo tanto, el coto vedado de los derechos constitucionales está justificado como un mecanismo de precompromiso para nuestras decisiones colectivas. Podría argumentarse, todavía, que la cultura de los derechos puede estar vigente en una sociedad y moldear sus decisiones colectivas sin necesidad de atrincherar los derechos en un Bill of Rights. Pero, es un hecho que las sociedades humanas en determinadas circunstancias tratan de oprimir a las minorías negando los derechos individuales de sus miembros. Obviamente, que la existencia de un Bill of Rights no es una muralla suficiente para la tiranía, ahora bien, constituye un instrumento susceptible de dificultar esas decisiones que violan derechos. Los mecanismos de precompromiso están diseñados para que tengamos mayores probabilidades de alcanzar los resultados deseados, por lo que si dichos mecanismos funcionan en las decisiones colectivas tenemos buenas razones para introducirlos en el diseño de nuestras instituciones políticas. La democracia constitucional representa un modelo adecuado de incorporación de dichos mecanismos.

Hasta ahora, sin embargo, nada he dicho del control jurisdiccional de constitucionalidad. Las razones para disponer de esta institución me parecen separables de las razones que justifican garantizar un coto vedado para los derechos básicos. El coto vedado de los derechos aumenta la probabilidad de que nuestras decisiones democráticas sean justas y, como he tratado de mostrar, no sólo no es incompatible con la idea de democracia sino que se corresponde con el modelo de democracia más adecuado a una teoría de la justicia que garantiza derechos individuales. Ahora bien, si el control jurisdiccional de constitucionalidad es un instrumento adecuado para asegurar el 
coto vedado de los derechos depende de consideraciones contingentes y estratégicas. En algunas sociedades y en algunos momentos, el mecanismo del control de constitucionalidad puede ser adecuado para aumentar la probabilidad de que las decisiones colectivas sean justas; en otras sociedades o en otros momentos, puede favorecer a minorías elitistas deseosas de mantener el statu quo. Por lo tanto, la conveniencia de los mecanismos de control judicial de la constitucionalidad depende de circunstancias históricas y contingentes.

De hecho, existen claros ejemplos de constituciones con declaraciones de derechos, que carecen de control judicial de constitucionalidad59. Del hecho de que no exista control judicial de constitucionalidad no se deriva que la Constitución -y la declaración de derechos en ella contenida- no juegue ningún papel en la política. Según Ronald Dworkin, por ejemplo, esta hubiera sido una posibilidad de la práctica constitucional norteamericana (una posibilidad que, para Dworkin afortunadamente, truncó el juez Marshall en el caso Marbury $v$. Madison) 60 :

It does not follow as a matter of iron logic that the Supreme Court should have the power to decide when these limits have been transgressed. For the Constitution might have been interpreted as laying down directions to Congress, the president, and state officials that these officers had a legal as well as a moral duty to follow, but making them their own judges. The Constitution would then have played a very different and much weaker role in American politics: it would have served as a background for political arguments among different institutions about the limits of their constituional jurisdiction rather as a source of the authority of one of these institutions, the courts, to fix those limits for the rest.

Que la última palabra la tenga la legislatura no significa que los argumentos constitucionales no tengan peso. Si los argumentos de la minoría parlamentaria son que un determinado proyecto de ley viola la declaración de derechos, entonces — presumiblemente- dichos argumentos tendrán más fuerza que si no fuera así. Si reformar la declaración de derechos requiere de una mayoría cualificada, el argumento de la minoría puede ir encaminado a mostrar que es exigible alcanzar esa mayoría para lograr ese cambio. Que este mecanismo de control sea insuficiente depende, según creo, de la cultura política en la cual opere.

En este sentido, Joseph Raz ha distinguido entre la cultura política básica de una sociedad, que incluye a la vez la distribución del poder (la división de poderes, el sistema federal) y algunos principios básicos referidos a los derechos 
y deberes de los individuos y del gobierno, y los arreglos más detallados y contingentes. Por ello, es aconsejable proteger la estabilidad de la cultura política básica mediante algunos instrumentos institucionales que la aíslen en alguna medida de las presiones de la política cotidiana. Dicha labor puede ser confiada, según Raz, a otra Cámara legislativa, o a un órgano judicial, o a presunciones para la interpretación de las leyes por parte de los jueces -de esta forma cree Raz que se protegen los derechos básicos en el Reino Unido-, o -añado yomediante la posibilidad de que un determinado número de personas pueda accionar los mecanismos para la convocatoria de un referéndum sobre una ley considerada inconstitucional. Sea como fuere, concluye Raz 'constitutional rights contribute to this process. They are part of the institutional protection of the basic political culture of society' 61 .

Sin embargo, creo que hay un aspecto en el cual la función de los jueces será inevitable. Es de sobras conocido que los derechos morales no son derechos absolutos sino derechos prima facie, puesto que los derechos entran a menudo en conflicto entre sí (e.g. el derecho de $A$ a la libertad de expresión entra en conflicto con el derecho de $B$ a la intimidad) 62 . A veces tal vez sea posible establecer algún tipo de orden jerárquico entre derechos capaz de regular casos genéricos, pero a menudo los conflictos surgirán en los casos individuales. Y, si no queremos convertir a las asambleas legislativas en órganos judiciales, habremos de reconocer que estos conflictos deberán dirimirlos los jueces. Si los derechos básicos no están protegidos constitucionalmente, la legislatura podrá cambiar el signo de esa jurisprudencia por mayoría; pero no podrá prever por adelantado todos los casos de conflicto posible. Tal vez esta sea una consideración demasiado obvia, pero si se tiene en cuenta que muchas de las decisiones de los órganos judiciales que controlan la constitucionalidad son de este tipo, no debe ser ignorada cuando nos preguntamos sobre la legitimidad del control de constitucionalidad. No siempre las decisiones de estos órganos son contramayoritarias, algunas veces sólo establecen soluciones a conflictos que la regla de la mayoría no puede resolver.

\section{CONCLUSIONES: EL PERÍMETRO DEL COTO VEDADO}

Las conclusiones de este trabajo pueden ser sintetizadas en las dos siguientes:

(i) Si se acepta una teoría de la justicia que contiene principios que establecen derechos básicos, entonces estamos comprometidos con un diseño 
de nuestras instituciones políticas que aumente la probabilidad de obtener decisiones políticas que no violen esos derechos básicos. Dado que la protección constitucional de los derechos básicos es un elemento, a menudo necesario, para tal fin, tenemos buenas razones para establecer un coto vedado de naturaleza constitucional para los derechos morales básicos.

(ii) El control jurisdiccional de la constitucionalidad de las leyes no es un requisito necesario, ni suficiente, para la protección de los derechos básicos. Por lo tanto, no es un requisito necesario de las instituciones políticas justas. Puede que, incluso, en algunas circunstancias, sea un elemento que dificulta la protección de los derechos básicos y, en estas circunstancias, no habrá razones para mantenerlo. Ahora bien, tampoco hay razones para pensar que es un procedimiento que siempre debe ser rechazado.

Como he mostrado en (III), Waldron rechaza ambas conclusiones. Voy a dedicar el resto de este epígrafe a tratar de contestar a algunas de sus objeciones.

Waldron no distingue, en mi opinión, con claridad entre (i) y (ii). Y, en concreto, usa a menudo argumentos que pueden tener cierta fuerza contra (ii) como si también fueran válidos contra (i). Veamos, sin embargo, cuáles son sus argumentos contra (i) en primer lugar.

Según Waldron, dado que desacordamos acerca de cuáles son los derechos básicos que deben estar en el coto vedado, entonces es mejor dejar esta decisión en manos de la mayoría parlamentaria. Si lo hacemos así podemos errar también, pero al menos habremos preservado los derechos de todos a la participación. Ahora bien, el desacuerdo al que Waldron se refiere no es tan grande como él parece pensar. Si los derechos son establecidos en el coto vedado de forma genérica y no detallada, si introducimos en la Constitución conceptos y no concepciones 63 el acuerdo puede ser bastante generalizado. De hecho, el mismo Waldron ha argumentado en favor de disponer en el derecho de conceptos contestados64 -es decir, conceptos tales que continuos debates acerca de su propio significado se entienden como útiles para algunas funciones importantes asociadas con el uso del término que los expresa- y ha añadido que ello puede ser importante en supuestos de provisiones constitucionales para introducir una amplia deliberación pública al respecto (haciendo referencia precisamente al caso de Nueva Zelanda referido en la nota 59)65:

We do not agree on many things in our society, but perhaps we can agree on this: that we are better society for continuing to argue about certain 
issues than we would be if such arguments were artificially or stipulatively concluded.

Disponer de una constitución de principios, en lugar de una constitución o una legislación detallista, parece una buena manera de alcanzar el objetivo que Waldron nos indica66. Y los conceptos de los derechos morales básicos son buenos candidatos a conceptos esencialmente contestados. Aunque la gran mayoría de nosotros acordamos en la importancia de la libertad de expresión, o del derecho a la vida, estamos en desacuerdo en cuáles son las mejores concepciones de los conceptos expresados por 'libertad de expresión' o 'derecho a la vida'. Por cierto, que ello también atenúa la crítica de Waldron referida al peligro de encerrar estos conceptos en rígidas fórmulas verbales. Debemos usar fórmulas canónicas genéricas que nos permitan compartirlas a pesar de nuestros desacuerdos y que nos permitan una deliberación franca y abierta sobre sus implicaciones.

Sin embargo, debo referirme a la crítica que Waldron realiza particularmente a la idea de precompromiso trasladada al diseño de nuestras instituciones políticas 67 . Según Waldron, la analogía entre el agente racional que prevé su debilidad de voluntad futura y el poder constituyente que prevé que la mayoría puede mañana tomar una decisión que viole los derechos básicos, no es totalmente persuasiva. $Y$ no lo es porque no se trata, como en el caso del fumador que quiere abandonar los cigarrillos o del bebedor que entrega la llave de su coche a un amigo para no conducir a medianoche, de un yo lúcido protegiendo a un yo menos lúcido (a un yo incompetente, que autoriza una medida de auto-paternalismo), sino de una sociedad cuyos miembros desacuerdan incluso en sus momentos más lúcidos acerca de los derechos que tienen. Una analogía mejor, según Waldron, sería la de una persona que duda acerca de las creencias religiosas. Un día opta por la fe de una religión en particular. Entonces decide no consultar más en el futuro su biblioteca privada de libros teológicos en la que tanto tiempo había consumido. Para ello, cierra su biblioteca y entrega la llave a un amigo con instrucciones de que nunca se la devuelva, aunque la solicite. Unos pocos meses después le pide la llave. Aunque este es un caso de precompromiso, semejante en este sentido al supuesto del amigo que entrega la llave del coche para no conducir ebrio, hay una importante diferencia: la persona convertida a la fe religiosa no es ahora menos capaz de tomar decisiones racionales que lo era con anterioridad. La democracia se parece más, conforme a Waldron, a este segundo supuesto. No hay razones para atar las manos de las legislaturas futuras, ellas no son menos racionales que la asamblea constituyente. 
Sin embargo, las asambleas constituyentes suelen usar una gran cantidad de deliberación para alcanzar un consenso sobre las materias de la cultura política básica. Una deliberación que no siempre está presente en los momentos de política normal (obviamente, sigo aquí las sugerencias de Ackerman anteriormente referidas). Volvamos al caso de la persona que se convierte a una determinada fe religiosa. Si esta conversión ha sido fruto de una deliberación sincera y profunda, que es muy importante para la vida de esta persona, tal vez tendría sentido que las instrucciones al amigo no sean: 'Nunca me entregues las llaves, aunque te las pida'; sino 'Si te pido las llaves, no me las entregues hasta que no haya estudiado otra vez y con profundidad los textos de la religión a la que me he convertido'. Tal vez esta regla podría evitar un abandono inconsciente de la religión abrazada que produciría consecuencias graves en la integridad moral de la persona. Esta es la analogía que creo se adecua a la idea del coto vedado de derechos constitucionales. La crítica de Waldron podría servir para los casos como el de la Ley Fundamental en Alemania que atrinchera los derechos de una vez para siempre, pero no para los casos en los que está previsto un mecanismo de reforma constitucional. Se requiere, entonces, que en las cuestiones que el poder constituyente consideró especialmente valiosas, el cambio deba realizarse después de una deliberación más amplia que la que se produce en la deliberación legislativa habitual.

Una forma habitual de proteger la supremacía de la constitución es dotarla de un mecanismo de reforma que requiera mayorías reforzadas. Tiene razón Waldron en que ello produce asimetría respecto a la decisión a tomar, una minoría tiene una especie de derecho de veto sobre la mayoría para mantener el statu quo. Ahora bien, si el proceso constitucional se realizó de acuerdo a los principios de justicia, tal vez esté justificado un procedimiento que haga costoso revisar el resultado de dicho proceso. Por otra parte, existen medios de dotar de mayor legitimidad democrática a la reforma constitucional, e.g. exigir la aprobación de la mayoría de los ciudadanos mediante referéndum (así lo hacen los art. 167 y 168 de la Constitución española de 1978).

Me referiré, para terminar, a la crítica dirigida particularmente al control judicial de constitucionalidad. En mi opinión, el control judicial de constitucionalidad es un instrumento que puede ser adecuado para proteger los derechos constitucionales, aunque no es un mecanismo necesario para la existencia de una democracia constitucional. En palabras de Ronald Dworkin68:

I do not mean that there is no democracy unless judges have the power to set aside what a majority thinks is right and just. Many institutional 
arrangements are compatible with the moral reading, including some that do not give judges the power they have in the American structure. But none of these varied arrangements is in principle more democratic than others. Democracy does not insist on judges having the last word, but it does not insist that they must not have it.

Voy a referirme solamente a una cuestión: si no somos partidarios de la tesis de la indeterminación radical, es posible distinguir los casos constitucionales claros de los casos constitucionales difíciles.

En los casos claros, y bajo el supuesto de que los derechos constitucionales reconocen los derechos establecidos por los principios de justicia, puede suceder que el legislador haya violado uno de esos derechos en sus disposiciones legislativas. Si el Tribunal anula esa decisión, entonces consigue una resultado más justo que el que tendríamos si el control judicial no existiera. Si el Tribunal no anula esa decisión, entonces estamos igual como si el Tribunal no existiera. Por lo tanto, en los casos claros en que el legislador promulga leyes inconstitucionales, el Tribunal aumenta la capacidad de alcanzar resultados justos. Obviamente, también podría suceder que el Tribunal declarara inconstitucional una ley que es claramente constitucional y que va destinada a la protección de un derecho constitucional. Entonces ese derecho quedaría menos protegido (pero no totalmente desprotegido, el Tribunal no puede derogar la Constitución) y además habrían sido dañados los derechos de participación política. Tiendo a pensar, sin embargo, que este segundo supuesto es más bien raro en los casos constitucionales claros.

En los casos difíciles la cuestión es más compleja. Tal vez, en estos casos, un cierto grado de deferencia a las decisiones legislativas sea exigible al Tribunal, con el fin de evitar que una pocas personas tomen decisiones contrarias a la mayoría democrática sobre cuestiones todavía ampliamente controvertidas en la sociedad. No indagaré aquí sobre cuál haya de ser el grado de deferencia en cuestión69. Ahora bien, deseo terminar señalando que por más que haya un procedimiento de control judicial de la constitucionalidad, esto no representa en ningún caso que la constitución sea lo que el Tribunal dice que es, existen procedimientos -aunque costosos- de reforma de la constitución y existe la voluntad continuada de la mayoría política que, tampoco sin costes, puede cambiar la composición del Tribunal o puede cambiar sus opiniones. En palabras de Rawls 70: 
The constituion is not what the Court says it is. Rather, it is what the people acting constitutionally through the other branches eventually allow the Court to say it is. 


\section{NOTAS}

1. Puede verse WALDRON, Jeremy (ed.): Nonsense upon Stilts. Bentham, Burke and Marx of the Rights of Man. London, Methuen, 1987; que contiene los pasajes más relevantes de BENTHAM, Jeremy: Anarchical Fallacies, en BOWRING, John (ed.): The Works of Jeremy Bentham, vol. II. Edinburgh, William Tait, 18381843, p. 489-534; BURKE, Edmund en O'BRIEN, Conor C. (ed.): Reflections on the Revolution in France. Penguin, Harmondsworth, 1969 y MARX, Karl: 'On the Jewish Question' en McLELLAN, David (ed.): Karl Marx: Selected Writings. Oxford, Oxford University Press, 1977. El libro de Waldron contiene también interesantes introducciones a los textos seleccionados así como un estudio conclusivo.

2. BENTHAM, Jeremy: cit. en nota 1, p. 501.

3. MacINTYRE, Alasdair: After Virtue. Notre Dame, University of Notre Dame, 1984; SANDEL, Michael: Liberalism and the Limits of Justice. Cambridge, Cambridge University Press, 1982; TAYLOR, Charles: Sources of the Self. Cambridge, Cambridge University Press, 1989 y WALZER, Michael: Spheres of Justice. New York, Basic Books, 1983.

4. Como es sabido, el locus classicus es BICKEL, Alexander M.: The Last Dangerous Branch. New Haven, Yale University Press, 1962.

5. DWORKIN, Ronald: 'Does Britain Needs a Bill of Rights?' en Freedom's Law. The Moral Reading of American Constitution. Oxford, Oxford University Press, 1996, p. 352-372.

6. WALDRON, Jeremy: 'A Right-Based Critique of Constitutional Rights' en Oxford Journal of Legal Studies, 13/1993, p. 18-51. Vd., en el mismo sentido, ALLAN, James: 'Bill of Rights and Judicial Power-A Liberal's Quandary' en Oxford Journal of Legal Studies, 16/1996, p. 337-352.

7. BAYÓN, Juan Carlos: 'Derechos, democracia y constitución', ponencia inédita presentada en una conferencia el 26 de agosto de 1996 en la Universidad de Palermo, Buenos Aires (Argentina).

8. GARGARELLA, Roberto: La justicia frente al gobierno. Sobre el carácter contramayoritario del poder judicial. Barcelona, Ariel, 1996.

9. MACKIE, J.L.: Ethics. Inventing Right and Wrong. Harmondsworth, Penguin, 1977.

10. MACKIE, J.L.: 'Can There Be A Right-Based Moral Theory?' en WALDRON, Jeremy (ed.): Theories of Rights. Oxford, Oxford University Press, 1984, p. 170-171. Eugenio BULYGIN, también defensor del nocognoscitivismo en materia moral, ha escrito en este sentido: 'Es claro que si no hay normas morales absolutas, objetivamente válidas, tampoco puede haber derechos humanos universalmente válidos. ¿Significa esto que no hay en absoluto derechos morales ...? ... nada impide hablar de derechos morales y de derechos humanos, pero tales derechos no pueden pretender una validez absoluta. Ellos sólo pueden ser interpretados como exigencias que se formulan al orden jurídico desde el punto de vista de un determinado sistema moral'. BULYGIN, Eugenio: 'Sobre el status ontológico de los derechos humanos' en Doxa, 4/1987, p. 83.

11. Vd., en este sentido, LAPORTA, Francisco J.: 'Sobre el concepto de derechos humanos' en Doxa, 4/1987, p. 32.

\section{DWORKIN, Ronald: Taking Rights Seriously. London, Duckworth, 1978, p. 169-173.}

13. Vd., con todo, una interesante defensa de las teorías fundadas en derechos en MACKIE, J.L: 'Can there be a Right-Based Moral Theory?', cit. en nota 10, p. 168-181 y una crítica a estas concepciones, que aboga por un fundamento plural de las teorías de la justicia, en RAZ, Joseph: The Morality of Freedom. Oxford, Oxford University Press, 1986, cap. 8 y RAZ, Joseph: 'Rights and Politics' en Indiana Law Journal, 71/1995, p. 27-44.

14. SUMNER, L.W.: The Moral Foundation of Rights. Oxford, Oxford University Press, 1987, p. 199.

15. WALDRON, Jeremy: 'Introduction' en WALDRON, Jeremy (ed.): Theories of Rights, cit. en nota 10, p. 1213.

16. Kant escribió: 'La mentira (en el sentido ético de la palabra), como falsedad deliberada, no precisa perjudicar a otros para que se la considere reprobable... Su causa pude ser la ligereza o la bondad, incluso puede perseguirse con ella un fin realmente bueno, pero el modo de perseguirlo es, por la mera forma, un 
delito del hombre contra su propia persona y una bajeza que tiene que hacerle despreciable a sus propios ojos'. KANT, Immanuel: La metafísica de las costumbres, trad. de A. Cortina Ors y J. Conill Sancho. Madrid, Tecnos, 1989, p. 292

17. BENTHAM, Jeremy: Supply without Burden; or Escheat vice Taxation en BENTHAM, Jeremy, (STARK, William (ed.)): Economic Writings, vol. I. London, George Allen \& Unwin, 1952-1954, p. 134 y BENTHAM, Jeremy: Pannomial Fragments en BENTHAM, Jeremy: The Works of Jeremy Bentham, vol. III, cit. en nota 1, p. 219.

18. Que así entendida la noción de derecho moral no es autocontradictoria ha sido también defendido por GUASTINI, Riccardo: 'Diritti' en Distinguendo. Studi di teoria e metateoria del diritto. Torino, Giappichelli, p. 149. En la filosofía del derecho reciente en lengua española se ha usado un argumento lingüístico para mostrar la inadecuación de la expresión española 'derechos morales' (vd., e.g., PECES-BARBA, Gregorio: 'Sobre el fundamento de los derechos humanos' en Anales de la Cátedra Francisco Suárez, 28/1988, p. 193207 y VERNENGO, Roberto J.: 'Los derechos humanos como razones morales justificatorias' en Doxa, $7 / 1990$, p. 275-297) porque, se dice, mientras el idioma inglés distingue entre 'derecho objetivo' (law) y derecho subjetivo (right), lo que le capacita a su vez para distinguir entre legal rights y moral rights; el idioma español (como el francés, el alemán o el italiano) sólo disponen de una expresión 'derecho', con lo que 'derecho jurídico' sería redundante y 'derecho moral' paradójico sino absurdo. Esta consideración lexicográfica me parece desconcertante: en primer lugar, de que un sólo término designe dos conceptos nada se infiere respecto a las conexiones entre ambos conceptos y, en segundo lugar, 'derecho' es usado en el sentido de 'derecho subjetivo' en múltiples ocasiones en español, en contextos claramente no jurídicos, así cuando le digo a un amigo 'tengo derecho a que tomes en serio mis observaciones'. Véanse las pertinentes críticas al respecto de LAPORTA, Francisco J.: 'Acotaciones del trampolín: Respuesta a Roberto Vernengo' en Doxa, 7/1990, p, 301 y NINO, Carlos S.: 'Sobre los derechos morales' en Doxa, 7/1990, p. 311-313.

19. Vd. un interesante análisis de este aspecto del pensamiento de Bentham en HART, H.L.A.: 'Natural Rights: Bentham and John Stuart Mill' en Essays on Bentham. Jurisprudence and Political Theory. Oxford, Oxford University Press, 1982, cap. IV. Valga destacar aquí que John STUART MILL (ROBSON, J.M (ed.): Utilitarianism en Collected Works of John Stuart Mill, vol 10. Toronto, University of Toronto Press, 1969, cap. V) consideraba los derechos morales como un importante aspecto de la justicia en su moral utilitarista.

20 . HOHFELD, Wesley N.: Fundamental Legal Conceptions as Applied in Judicial Reasoning. New Haven, Yale University Press, 1919.

21. Un interesante análisis que desarrolla las ideas de Hohfeld puede verse en ROSS, Alf: On Law and Justice. London, Stevens \& Sons, 1958, p. 158-169. Para algunos análisis de Bentham que prefiguran el análisis hohfeldiano, vd. HART, H.L.A.: 'Legal Rights' en Essays on Bentham, cit. en nota 19, p. 162-193 y MORESO, José Juan: La teoría del Derecho de Bentham. Barcelona, P.P.U., 1992, p. 216-225.

22. No se indagará aquí sobre la naturaleza de las reglas que confieren poderes.

23. Defendida en un momento por HART, H.L.A.: 'Are there Any Natural Rights' en WALDRON, Jeremy (ed.): Theories of Rights, cit. en nota 10, p. 77-90.

24. LYONS, David: 'Rights, Claimants, and Beneficiaries' en American Philosophical Quarterly, 6/1969, p. 173-185; MacCORMICK, Neil: 'Legal Rights' en HACKER, P.M.S. y RAZ, J. (eds.): Law, Morality, and Society. Essays in Honour of H.L.A. Hart. Oxford, Oxford University Press, 1978, p. 189-209; RAZ, Joseph: The Morality of Freedom, cit. en nota 13, cap. 7 y NINO, Carlos S.: Etica y Derechos Humanos. Buenos Aires, Astrea, 1989, p. 31-40.

25. LAPORTA, Francisco J.: 'Sobre el concepto de derechos humanos' en Doxa, 4/1987, p. 23-46.

26. SUMNER, L.W.: The Moral Foundation of Rights, cit. en nota 14, p. 137.

27. WALDRON, Jeremy: 'A Right-Based Critique of Constitutional Rights', cit. en nota 6, p. 19.

28. Ibídem, p. 24.

29. Ibídem, p. 24.

30. Para que esta derivación sea correcta, hace falta explicitar la premisa (implícita) de carácter moral según la cual el derecho debe adecuarse a la moralidad. 
31. GARZÓN VALDÉS, Ernesto: 'Representación y democracia' en GARZÓN VALDÉS, Ernesto: Derecho, Ética y Política. Madrid, Centro de Estudios Constitucionales, 1993, p. 644-645.

32. WALDRON, Jeremy: cit. en nota 6, p. 25-27. Como puede apreciarse estos ejemplos están tomados de la discusión norteamericana sobre el alcance de la primera enmienda de la Constitución de los Estados Unidos.

33. Ibídem, p. 26-28.

34. Ibídem, p. 32.

35. WALDRON, Jeremy: ‘Freeman's Defense of Judicial Review' en Law and Philosophy, 13/1994, p. 35-36.

36. GARGARELLA, Roberto: La justicia frente al gobierno, cit. en nota 8, caps. 1 y 2.

37. WALDRON, Jeremy: cit. en nota 6, p. 50.

38. RAWLS, John: A Theory of Justice. Cambridge, Mass., Harvard University Press, 1971, p. $85-87$ y Political Liberalism. New York, Columbia University Press, 1993, p. 72-73.

39. RAWLS, John: Political Liberalism, cit. en nota 38, p. 72.

40. RAWLS, John: A Theory of Justice, cit. en nota 38, p. 198. Vd. también, FREEMAN, Samuel: 'Constitutional Democracy and the Legitimacy of Judicial Review' en Law and Philosophy, 9/1990-1991, p. 336-337 y FERRERES COMELLA, Víctor: Justicia constitucional y democracia, manuscrito. Barcelona, Universidad Pompeu Fabra, 1996, p. 99-100. Incluso Waldron comparte esta apreciación, vd. WALDRON, Jeremy: 'Freeman's Defense of Judicial Review', cit. en nota 35, p. 28-29.

41. Como tomo la teoría de Rawls en cuenta supondré que los principios de justicia son los dos principios rawlsianos: un derecho igual al sistema de libertades total más extenso de libertades básicas compatible con un sistema similar de libertades para los demás y las desigualdades económicas y sociales han de estructurarse de manera que redunden en mayor beneficio para los más desaventajados y los cargos y las funciones han de ser asequibles a todos, bajo condiciones de justa igualdad de oportunidades. Vd. RAWLS, John: A Theory of Justice, cit. en nota 38, p. 302. Ahora bien, nada en mi argumento lo hace dependiente de la peculiar concepción rawlsiana de la justicia.

42. DAHL, Robert: Democracy and Its Critics. New Haven, Yale University Press, 1989, p. 156-167.

43. ACKERMAN, Bruce: 'Constitutional Politics/Constitutional Law' en Yale Law Journal, 99/1989, p. 486-515.

44. NINO, Carlos S.: 'La filosofía del control judicial de constitucionalidad' en Revista del Centro de Estudios Constitucionales, 4/1989, p. 86-87, NINO, Carlos S.: Etica y Derechos Humanos, cit. en nota 24, p. 387-400 y NINO, Carlos S.: Fundamentos de Derecho Constitucional. Buenos Aires, Astrea, p. 203-209.

45. Una posición brillantemente defendida por John Hart ELY, Democracy and Distrust. A Theory of Judicial Review. Cambridge, Mass., Harvard University Press, 1980. De hecho, Nino añade otras razones que justifican en su opinión el control judicial de la constitucionalidad: así la preservación de la autonomía individual y la necesidad de asegurar la continuidad de la práctica constitucional; sin embargo, ahora me interesa subrayar el argumento del control interno del procedimiento democrático, vd. NINO, Carlos S.: Fundamentos de Derecho Constitucional, cit. en nota 44, p. 692-702.

46. WALDRON, Jeremy: 'A Right-Based Critique of Constitutional Rights', cit. en nota 6, p. 39.

47. RAWLS, John: A Theory of Justice, cit. en nota 38, p. 195-201.

48. RAWLS, John: Political Liberalism, cit. en nota 38, p. 227.

49. Ibídem, p. 229-230.

50. Ibídem, p. 233.

51. FREEMAN, Samuel: 'Constitutional Democracy and the Legitimacy of Judicial Review', cit. en nota 40.

52. RAWLS, John: $A$ Theory of Justice, cit. en nota 38, p. 362. 
53. RAWLS, John: Political Liberalism, cit. en nota 38, p. 234-235 y DAHL, Robert: Democracy and Its Critics, cit. en nota 42, p. 192.

54. La primera parte de este epígrafe es una reelaboración de las primeras páginas del cap. IV de MORESO, José Juan: La indeterminación del Derecho y la interpretación de la Constitución. Madrid, Centro de Estudios Constitucionales, en prensa.

55. ELSTER, Jon: Ulysses and the Syrens. Cambridge, Cambridge University Press, 1979, p. 94. Vd. también HOLMES, Stephen: 'Precomittment and the Paradox of Democracy' en ELSTER, Jon y SLAGSTAD, Rune (eds.): Constituionalism and Democracy. Cambridge, Cambridge University Press, 1988, p. 222.

56. ELSTER, Jon: Ulysses and the Syrens, cit. en nota 55, p. 36.

57. Ibídem, p. 94; vd. también una distinción semejante entre política constitucional y política normal en ACKERMAN, Bruce: 'The Storrs Lectures: Discovering the Constitution' en Yale Law Journal, 93/1984, p. 1029.

58. HUME, David en SELBY-BIGGE, L.A. (ed.): A Treatise of Human Nature. Oxford, Oxford University Press, 1978, p. 484-502.Vd. también HART, H.L.A.: The Concept of Law. Oxford, Oxford University Press, 1961, p. 189-195 y RAWLS, John: A Theory of Justice, cit. en nota 38, p. 126-127. Una analogía semejante en FREEMAN, Samuel: 'Constitutional Democracy and the Legitimacy of Judicial Review', cit. en nota 40, p. 360363.

59. En 1990, en Nueva Zelanda se estableció un Bill of Rights, sin embargo los jueces tienen expresamente prohibido declarar inválidas las disposiciones legislativas por ser contrarias a dicho Bill of Rights. Vd. ALLAN, James: 'Bill of Rights and Judiciary Power-A Liberal's Quandary', cit. en nota 6, p. 348, nota 49. En Canadá, después de la promulgación en 1982 de la 'Charter of Rights and Freedoms' se estableció un mecanismo (vía la 'notwithstanding clause') por el cual, la última palabra la tiene el poder legislativo. Esto es, aunque un Tribunal considere contraria a alguno de los derechos de la Carta una determinada disposición legislativa, la legislatura tiene la última palabra para mantenerla en vigor. Vd. sobre esta técnica de reenvío, GARGARELLA, Roberto: La justicia frente al gobierno, cit. en nota 8, p. 174-177.

60. DWORKIN, Ronald: Law's Empire. Cambridge, Mass., Harvard University Press, 1986, p. 355-356.

61. RAZ, Joseph: The Morality of Freedom, cit. en nota 13, p. 257-260.

62. J.L. Mackie escribió: 'This means that the rights we have called fundamental can be no more than prima facie rights: the rights that in the end people have, their final rights, must result from compromises between their initially conflicting rights'. MACKIE, J.L.: 'Can There Be A Right-Based Moral Theory', cit. en nota 10, p. 177.

63. DWORKIN, Ronald: Taking Rights Seriously, cit. en nota 12, p. 134-136.

64 . En el sentido de GALLIE, W.B.: 'Essentially Contested Concepts' en Proceedings of Aristotelian Society, 56/1955-1956, p. 167-198.

65. WALDRON, Jeremy: 'Vagueness in Law and Language: Some Philosophical Issues' en California Law Review, 82/1994, p. 539-540. Esta consideración acerca de la posición de Waldron me fue sugerida por Víctor Ferreres, al que quedo sinceramente agradecido.

66. Para la distinción entre una constitución de principios y una constitución de detalle, vd. DWORKIN, Ronald: Life's Dominion. London, Harper Collins, 1993, cap. 5.

67. WALDRON, Jeremy: 'A Right-Based Critique of Constitutional Rights', cit. en nota 6, p. $46-49$ y WALDRON, Jeremy: 'Freeman's Defense of Judicial Review', cit. en nota 35, p. 36-39.

68. DWORKIN, Ronald: 'Introduction: The Moral Reading and the Majoritarian Premise' en Freedom's Law, cit. en nota 5 , p. 7.

69. Un lúcido análisis de esta cuestión en FERRERES COMELLA, Víctor: Justificación constitucional y democracia, cit. en nota 40, especialmente cap. 5 .

70. RAWLS, John: Political Liberalism, cit. en nota 38, p. 237. 
